\title{
Incidence of cesarean section among primi at a tertiary care hospital in Mahabubnagar, Telangana, India
}

\author{
Janaki Vellanki* \\ Department of Obstetrics and Gynecology, Government Medical College, Mahabubnagar, Telangana, India \\ Received: 18 September 2018 \\ Accepted: 22 October 2018 \\ *Correspondence: \\ Dr. Janaki Vellanki, \\ E-mail: janaki1224@gmail.com \\ Copyright: () the author(s), publisher and licensee Medip Academy. This is an open-access article distributed under \\ the terms of the Creative Commons Attribution Non-Commercial License, which permits unrestricted non-commercial \\ use, distribution, and reproduction in any medium, provided the original work is properly cited.
}

\begin{abstract}
Background: Not only in India but globally the incidence of cesarean section deliveries is increasing and it is becoming an important cause of concern. The objective of the present study was to observe the incidence of cesarean section deliveries at a tertiary care hospital.

Methods: A hospital record-based study was carried out from January 2017 to August 2018. All deliveries with live birth taking place among the primipara were included in the present study. Other than this was excluded. Data was analyzed using proportions.

Results: A total of 12254 deliveries took place from January 2017 to August 2018. Maximum deliveries were seen during July 2017 to October 2017 where it ranged above 6\%. Normal delivery rate ranged from 51.2\% in March 2018 to $64.4 \%$ in February 2017. Overall it was $62.1 \%$. The overall cesarean section rate was $37.9 \%$ in the present study. This rate is very low compared to the rates from private sector. The cesarean section rate ranged from $35.6 \%$ in February 2017 which was lowest in the study period to $48.8 \%$ in the month of March 2018 which was the highest in the study period. But the cesarean section rate never crossed the 50\% mark and most of the time it remained near $40 \%$ mark.

Conclusions: It has been found that the cesarean section rate always remained on a lower side as compared to the normal deliveries rate. This can be attributed to the appropriate clinical practices in our settings.
\end{abstract}

Keywords: Cesarean section, Healthy normal delivery, Primipara

\section{INTRODUCTION}

Not only in India but globally the incidence of cesarean section deliveries is increasing and it is becoming an important cause of concern. ${ }^{1}$

Delivery by cesarean section has been considered as more dangerous in terms of maternal health as compared to the vaginal deliveries. The fetus would not be getting any additional advantage in the delivery by cesarean section as compared to the delivery by vaginal route. Various reasons have been cited for this increased in the rates of cesarean section deliveries. ${ }^{2}$ The various reasons may be labor inductions, women preference towards cesarean section as they think that it is painless, it can be done at any preferred time, etc. ${ }^{3}$

Vertex presentation is an indication of normal vaginal delivery. But if the mother presents with prolapse of cord, major placenta previa and malpresentation then these are standard indications for cesarean section.

Such indications have been included as guidelines for carrying out cesarean section in developed countries and they are properly followed. ${ }^{4}$ Data from "South Asian and sub-Saharan African countries" indicates that the 
cesarean section is more common among rich people from urban areas and less than 5\% among people who are poor and are from rural areas. ${ }^{5}$

Cesarean section carried out without appropriate indications can lead to the damage of the mother and child. World Health Organization in its survey 2008 report which was carried out in 24 countries found that cesarean section done without actual indication compared to the normal vaginal delivery was associated with poor maternal and fetal outcomes, increased maternal mortality. Neonatal mortality has also been found to be strongly associated with cesarean section rates especially in countries with low resource settings.

Financially also this has resulted in the undue expenses for the families. ${ }^{6}$ The cesarean section rates increased from $2 \%$ in the year 2000 to $17 \%$ in the year 2011 in Bangladesh, from 3\% in 1992 to $11 \%$ in 2006 in India, from $1 \%$ in 2000 to $5 \%$ in 2011 in Nepal. ${ }^{7}$ Present study was carried out to study the incidence of cesarean section among primi at a tertiary care hospital.

\section{METHODS}

Present study was hospital based retrospective study. The hospital records of Obstetrics and Gynecology department from January 2017 to August 2018 were studied. The study was carried out at Department of Obstetrics and Gynecology, Government Medical College, Mahabubnagar, Telangana State. During the study period of January 2017 to August 2018 total of 12254 primi deliveries took place at Obstetrics and Gynecology, Government Medical College, Mahabubnagar, Telangana State and all of these were included in the present study. Institutional Ethics Committee permission was obtained for the present study. Permission from Medical Superintendent was obtained to publish the results of the present study.

\section{Inclusion criteria}

- Only primipara deliveries included

- Both normal as well as lower segment cesarean section delivery.

\section{Exclusion criteria}

- Multipara deliveries excluded.

Hospital records from Obstetrics and Gynecology, Government Medical College, Mahabubnagar; Telangana State from January 2017 to August 2018 was studied. Only primipara deliveries that took place during the study period were included and deliveries of multipara were excluded.

It was found that a total of 12254 deliveries took place during this one-and-a-half-year period. Out of this, 7610 $(62.1 \%)$ were normal and $5356(37.9 \%)$ were delivered by lower segment cesarean section. Month wise analysis was carried out for both the normal deliveries as well as for the deliveries by lower segment cesarean section.

\section{Statistical analysis}

The data was entered in the Microsoft Office Excel Worksheet. The data was then analyzed using proportions.

\section{RESULTS}

A total of 12254 deliveries took place from January 2017 to August 2018. Maximum deliveries were seen during July 2017 to October 2017 where it ranged above 6\%. Again, it is going above 6\% in July 2018. From March 2017 to May 2017 the delivery rate was less than $5 \%$. From November 2017 to June 2018 the delivery rate varied between $5-6 \%$.

Table 1: Month wise distribution of total deliveries.

\begin{tabular}{|lll|}
\hline Month & Number & $\%$ \\
\hline January 2017 & 476 & 3.9 \\
\hline February 2017 & 413 & 3.4 \\
\hline March 2017 & 551 & 4.5 \\
\hline April 2017 & 567 & 4.6 \\
\hline May 2017 & 563 & 4.5 \\
\hline June 2017 & 655 & 5.3 \\
\hline July 2017 & 763 & 6.2 \\
\hline August 2017 & 752 & 6.1 \\
\hline September 2017 & 782 & 6.4 \\
\hline October 2017 & 772 & 6.3 \\
\hline November 2017 & 712 & 5.8 \\
\hline December 2017 & 689 & 5.6 \\
\hline January 2018 & 712 & 5.8 \\
\hline February 2018 & 652 & 5.3 \\
\hline March 2018 & 713 & 5.8 \\
\hline April 2018 & 693 & 5.7 \\
\hline May 2018 & 734 & 5.9 \\
\hline June 2018 & 659 & 5.4 \\
\hline July 2018 & 781 & 6.4 \\
\hline August 2018 & 327 & 2.7 \\
\hline Total & 12254 & 100 \\
\hline
\end{tabular}

Normal delivery rate ranged from 51.2\% in March 2018 to $64.4 \%$ in February 2017. It was above $60 \%$ from January 2017 to May 2017; then gone down below 60\% in June and July 2017; then in August 2017 went above $60 \%$ and again came down below $60 \%$ from September 2017 to November 2017. In December 2017 and January 2018 , it was above $60 \%$ and then it was consistently below 60\% from February 2018 to August 2018. Overall it was $62.1 \%$. The overall cesarean section rate was $37.9 \%$ in the present study. This rate is very low compared to the rates from private sector. The cesarean section rate ranged from $35.6 \%$ in February 2017 which was lowest in the study period to $48.8 \%$ in the month of March 2018 which was the highest in the study period. 
Table 2: Month wise distribution of normal deliveries.

\begin{tabular}{|lll|}
\hline Month & Number & $\%$ \\
\hline January 2017 & 289 & 60.7 \\
\hline February 2017 & 266 & 64.4 \\
\hline March 2017 & 341 & 61.9 \\
\hline April 2017 & 357 & 62.9 \\
\hline May 2017 & 354 & 62.9 \\
\hline June 2017 & 381 & 58.2 \\
\hline July 2017 & 437 & 57.3 \\
\hline August 2017 & 454 & 60.4 \\
\hline September 2017 & 452 & 57.8 \\
\hline October 2017 & 433 & 56.1 \\
\hline November 2017 & 413 & 58 \\
\hline December 2017 & 429 & 62.3 \\
\hline January 2018 & 455 & 63.9 \\
\hline February 2018 & 380 & 58.3 \\
\hline March 2018 & 365 & 51.2 \\
\hline April 2018 & 373 & 53.8 \\
\hline May 2018 & 420 & 57.4 \\
\hline June 2018 & 378 & 57.4 \\
\hline July 2018 & 445 & 56.9 \\
\hline August 2018 & 188 & 57.5 \\
\hline Total & 7610 & 62.1 \\
\hline
\end{tabular}

But the cesarean section rate never crossed the $50 \%$ mark and most of the time it remained near $40 \%$ mark.

Table 3: Month wise distribution of deliveries by lower segment cesarean section.

\begin{tabular}{|lll|}
\hline Month & Number, LSCS & $\%$ \\
\hline January 2017 & 187 & 39.3 \\
\hline February 2017 & 147 & 35.6 \\
\hline March 2017 & 210 & 38.1 \\
\hline April 2017 & 210 & 37.1 \\
\hline May 2017 & 209 & 37.1 \\
\hline June 2017 & 274 & 41.8 \\
\hline July 2017 & 326 & 42.7 \\
\hline August 2017 & 298 & 39.6 \\
\hline September 2017 & 330 & 42.2 \\
\hline October 2017 & 339 & 43.9 \\
\hline November 2017 & 299 & 42 \\
\hline December 2017 & 260 & 37.7 \\
\hline January 2018 & 257 & 36.1 \\
\hline February 2018 & 272 & 41.7 \\
\hline March 2018 & 348 & 48.8 \\
\hline April 2018 & 320 & 46.2 \\
\hline May 2018 & 314 & 42.6 \\
\hline June 2018 & 281 & 42.6 \\
\hline July 2018 & 336 & 43.1 \\
\hline August 2018 & 139 & 42.5 \\
\hline Total & 5356 & 37.9 \\
\hline
\end{tabular}

Figure 1 shows comparison between cesarean section rates and normal deliveries rates month wise. It has been found that the cesarean section rate always remained on a lower side as compared to the normal deliveries rate and as seen from the above figure, a wide gap has been maintained between the two in all successive months. This can be attributed to the appropriate clinical practices in our settings.

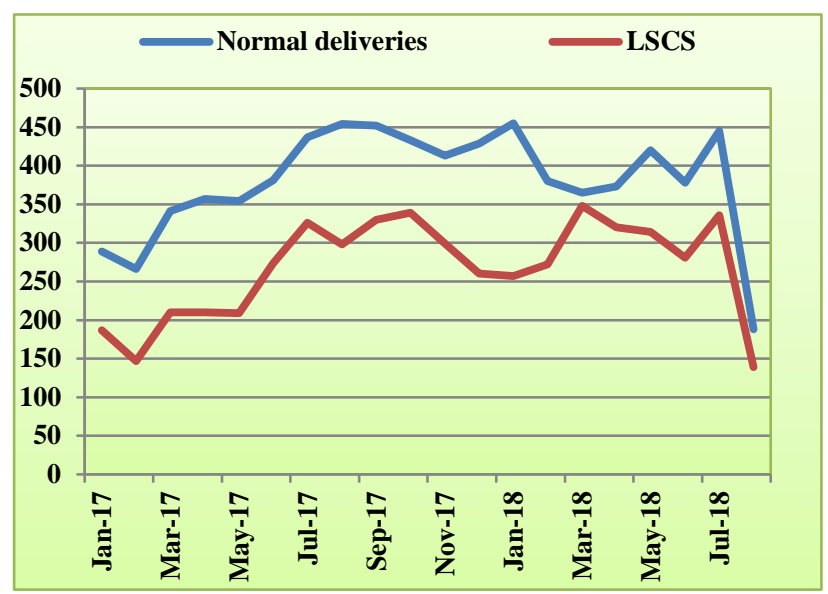

Figure 1: Comparison of normal deliveries and cesarean section delivery rates month wise.

\section{DISCUSSION}

A total of 12254 deliveries took place during the study period and out of them $37.9 \%$ were done by cesarean section and rest were normal vaginal deliveries in the present study.

Davey MA et al in their study found that onset of labor was not associated with perinatal deaths. Women who underwent induction of labor were at 2.54 times more at risk of cesarean section than the women who did not underwent the induction of labor. ${ }^{8}$ The authors concluded that induction of labour in normal women leads to more incidence of cesarean section. Thus, authors suggested that inductions should be minimized if not indicated which will lead to the reduced number of cesarean sections. ${ }^{8}$

Janoudi $G$ et al noted that as the age of the mother was more, the rate of cesarean section was also increased from $26.2 \%$ in the age group of 20-34 years to $35.9 \%$ in the age group of $35-40$ years and $43.1 \%$ in the age group of above 40 years. ${ }^{9}$ We also found similar rates of cesarean section in the present study. Factors like cesarean section done in the last delivery time, primiparity, gestational diabetes, hypertension of chronic nature, other medical conditions, were more commonly associated with the increased rates of cesarean section. The authors concluded from their study that only medical conditions are not responsible for the increased rates of the cesarean section, but the individual preferences are also important, and more studies should be done related to this. ${ }^{9}$

Betran AP et al 10 studied data on cesarean sections from 150 countries and observed that the average rate for the 
cesarean section was $18.6 \%$ overall and ranged from 6$27.2 \%$. This is slightly higher in the present study at $37.9 \%$. The authors found that the highest rates of the cesarean section were $40.5 \%$ in the Caribbean region. This rate is also higher than the rate in the present study. The rates for Asia are $19.2 \%$ as given by the author and this is very low compared to the finding of the present study. The authors concluded that the rates of cesarean section have increased globally. ${ }^{10}$

Saha L et al studied 100 cases and found that the overall rate of the cesarean section was $57.87 \%$ which is very high compared to the present study where we found it as $37.9 \% .^{11}$ The authors mentioned that out of these, $74.34 \%$ were primary cesarean section deliveries. Just like present study, this study also focused on the primigravida women. In $35 \%$ of the cases the indication for the cesarean section was fetal distress, in $14 \%$ of the cases the indication for the cesarean section was pre-eclampsia, in $12 \%$ of the cases the indication for the cesarean section was cervical dystocia. In $70 \%$ of the cases it was emergency cesarean section while the rest were elective. $^{11}$

Al-Kadri HM et al studied 198 gravid one woman and 200 gravida two women. They noted that lack of antenatal care in G2 was the most common cause of increased cesarean sections and the difference was found to be statistically significant. ${ }^{12}$ Previous vaginal surgery was another important risk factor for increased rate of cesarean section for G2 women. These G2 women who had previous vaginal surgery were found to be at 10 times more risk of undergoing cesarean section than women who never had previous vaginal surgery. The authors concluded that physician practice appears to be responsible for increased rates of the cesarean section and can be reduced. ${ }^{12}$

Al Rowaily MA et al observed that during the period of four years the cesarean section rte was $19.05 \%$ which is very low compared to the findings of the present study where we found that it was $37.9 \%$. This may be due to the difference in the study period. ${ }^{13}$ Where we studied only for 18 months the authors studied the rate over a period of four years. The authors noted that the $67 \%$ of the total cesarean sections were emergency in nature and $33 \%$ were elective in nature. In $35.9 \%$ of the cases the indication for emergency cesarean section was difficult labor, in $21.9 \%$ of the cases the indication for emergency cesarean section was fetal distress, in $11.6 \%$ of the cases, the indication was for emergency cesarean section breech presentation. In $54.3 \%$ of the cases previous cesarean section was the indication for elective cesarean section, in $20.4 \%$ of the cases breech presentation was the indication for elective cesarean section, in $10.1 \%$ of the cases maternal request was the indication for elective cesarean section. The authors recommended that more studies are required on repeat cases of cesarean section. ${ }^{13}$ Kamil A et al found that pre-maturity of the fetus, parity and advanced age of the mother were prominent risk factors for increased rates of cesarean section. ${ }^{14}$ The authors recommended that certain secondary tests should be done during pregnancy to ensure that fetus is all right and this may help reduce the cesarean section delivery rates. ${ }^{14}$

Ahmed I et al noted the effect of counselling on the rates of cesarean section. ${ }^{15}$ They observed that the rates of the cesarean section were more among women who were not given counselling during pregnancy and who were not attended by full time faculty. But the differences were not found to be statistically significant. The authors concluded that the standard guidelines should be followed to reduce the physician bias. They recommended more studies especially with large sample size and multiple centre studies and prospective studies. ${ }^{15}$

\section{CONCLUSION}

It has been found that the cesarean section rate always remained on a lower side as compared to the normal deliveries rate. This can be attributed to the appropriate clinical practices in our settings. Though more compared to certain studies from other countries, but lesser than compared to the settings in the private sector.

Funding: No funding sources

Conflict of interest: None declared

Ethical approval: The study was approved by the Institutional Ethics Committee

\section{REFERENCES}

1. Kozhimannil KB, Law MR, Virnig BA. Cesarean delivery rates vary tenfold among US hospitals; reducing variation may address quality and cost issues. Health Aff (Millwood). 2013;32(3):527-35.

2. Luthy DA, Malmgren JA, Zingheim RW Cesarean delivery after elective induction in nulliparous women: the physician effect. Am J Obstet Gynecol. 2004;191(5):1511-5.

3. Kottmel A, Hoesli I, Traub R, Urech C, Huang D, Leeners B et al. Maternal request: a reason for rising rates of cesarean section? Arch Gynecol Obstet. 2012;286(1):93-8.

4. Manohar S, Woods CF, Lindow SW. Individual consultant practice does not affect the overall intervention rate: a 6-year study. J Perinat Med. 2015;43(1):37-41.

5. Cavallaro FL, Cresswell JA, França GV, Victora CG, Barros AJ, Ronsmans C. Trends in caesarean delivery by country and wealth quintile: crosssectional surveys in southern Asia and sub-Saharan Africa. Bull World Health Organ. 2013;91(12):914922D.

6. Gibbons L, Belizán JM, Lauer JA, Betrán AP, Merialdi M, Althabe F. The global numbers and costs of additionally needed and unnecessary caesarean sections performed per year: overuse as a barrier to universal coverage. World Health Report. 2010;30:1-31. 
7. Leone T, Padmadas SS, Matthews Z. Community factors affecting rising caesarean section rates in developing countries: an analysis of six countries. Soc Sci Med. 2008;67(8):1236-46.

8. Davey MA, King J. Caesarean section following induction of labour in uncomplicated first births- a population-based cross-sectional analysis of 42,950 births. BMC Pregnancy Childbirth 2016;16(1):92.

9. Janoudi G, Kelly S, Yasseen A, Hamam H, Moretti F, Walker M. Factors Associated With Increased Rates of Caesarean Section in Women of Advanced Maternal Age. J Obstet Gynecol Can 2015;37(6):517-26.

10. Betran AP, Ye J, Moller AB, Zhang J, Gulmezoglu AM, Torloni MR. The Increasing Trend in Caesarean Section Rates: Global, Regional and National Estimates: 1990-2014. PLoS One 2016;11(2): e0148343.

11. Saha L, Chowdhury SB. Study on primary cesarean section. Mymensingh Med J. 2011;20(2):292-7.

12. Al-Kadri HM, Al-Anazi SA, Tamim HM. Increased cesarean section rate in Central Saudi Arabia: a change in practice or different maternal characteristics. Int J Womens Health. 2015;7:685-92.

13. Al Rowaily MA, Alsalem FA, Abolfotouh MA. Cesarean section in a high-parity community in Saudi Arabia: clinical indications and obstetric outcomes. BMC Pregnancy Childbirth 2014;14(1):92.

14. Kamil A, Perveen K, Al-Tannir MA. Factors associated with cesarean deliveries at Women Specialized Hospital Riyadh, King Fahd Medical City, Kingdom of Saudi Arabia. J Egypt Public Health Assoc. 2011;86(3-4):73-6.

15. Ahmed I, Shahwar D, Akhtar M, Amerjee A. Caesarean Section rate amongst Obstetricians at a tertiary-care hospital of Karachi. Pak J Med Sci 2018;34(3):553-7.

Cite this article as: Vellanki J. Incidence of cesarean section among primi at a tertiary care hospital in Mahabubnagar, Telangana, India. Int J Reprod Contracept Obstet Gynecol 2018;7:4934-8. 